\title{
QUESTÕES DE GÊNERO NA EDUCAÇÃO FíSICA ESCOLAR: uma análise nas zonas distritais de Rio Grande-RS
}

\section{GENDER ISSUES IN SCHOOL PHYSICAL EDUCATION: an analysis in the district zones of Rio Grande-RS}

\section{CUESTIONES DE GÉNERO EN LA EDUCACIÓN FÍSICA escolar: un análisis en las zonas de distrito de Rio Grande-RS}

iD Thais Mortola Dias
Universidade Federal de Pelotas - UFPel; Rio Grande; Rio Grande do Sul - RS; Brasil; E-mail: thais-mortola@hotmail.com

iD Giovanni Frizzo

Universidade Federal de Pelotas - UFPel; Pelotas; Rio Grande do Sul - RS; Brasil; E-mail: gfrizzo2@gmail.com

\begin{abstract}
Resumo: Temos por objetivo, neste trabalho, analisar como as questões de gênero são tratadas nas aulas de Educação Física (EF) da rede municipal de ensino da cidade de Rio Grande - RS, além de identificar o posicionamento dos professores e professoras sobre a temática gênero ser trabalhada nas aulas de EF. Para tanto, realizamos uma pesquisa qualitativa de cunho exploratório/descritivo. Percebemos que a escola ainda é um espaço que segrega e diferencia, visto que os estereótipos, as opressões, divisões e diferenciações entre os gêneros estão presentes. Constatamos os pró-discussão e os contra discussão, dois grupos distintos que se formaram quando os professores e as professoras ponderaram sobre a temática gênero ser tratada nas aulas de EF.
\end{abstract}

Palavras-chave: Questões de gênero. Sociedade. Escola. Educação Física. 


\begin{abstract}
In this work we aim to analyze how gender issues are dealt with in Physical Education (PE) classes at the municipal education network in the city of Rio Grande - RS, in addition to identifying the position of male and female teachers on the theme of gender being worked on in PE classes. To this end, we conducted a qualitative research of an exploratory / descriptive nature. We realize that the school is still a space that segregates and differentiates, since stereotypes, oppressions, divisions and differentiations between genders are present there. We found pro-discussion and counter-discussion, two distinct groups that were formed when teachers pondered the gender theme to be addressed in PE classes.
\end{abstract}

Keywords: Gender issues. Society. School. Physical Education.

Resumen: En este trabajo pretendemos analizar cómo se abordan las cuestiones de género en las clases de Educación Física (EF) de la red educativa municipal de la ciudad de Rio Grande - RS, además de identificar la posición de docentes y maestras en la temática de género que se trabaja en las clases de EF. Para ello, realizamos una investigación cualitativa de carácter exploratorio / descriptivo. Nos damos cuenta de que la escuela sigue siendo un espacio que segrega y diferencia, ya que allí están presentes estereotipos, opresiones, divisiones y diferenciaciones entre géneros. Encontramos pro-discusión y contra-discusión, dos grupos distintos que se formaron cuando los docentes reflexionaron sobre el tema de género a ser abordado en las clases de EF.

Palabras clave: Cuestiones de género. Sociedade. Colégio. Educacion Física.

Submetido em: 18-03-2021

Aceito em: 07-07-2021 
QUESTÕES DE GÊNERO NA EDUCAÇÃO FÍSICA ESCOLAR: uma análise nas zonas distritais... Thais Mortola Dias • Giovanni Frizzo

\section{Introdução}

Longe de ser um conceito neutro, o termo gênero nos possibilita analisar a ideologia patriarcal e a estrutura de poder, sendo que ambas auxiliam no processo de desigualdade entre mulheres e homens (SAFFIOTI, 2004). Martins (1998) ainda coloca que gênero é um fenômeno histórico que se define por meio das relações sociais e é uma forma de compreender determinadas relações de poder.

Essas relações ocorrem dentro de um modelo de sociedade patriarcal-racista-capitalista (CISNE, 2018) e é a partir desse modelo que as relações sociais se desenvolvem e que as relações de poder se intensificam. Machismo, racismo e capitalismo são estruturas fundamentais desse sistema de dominação-exploração que vivemos, visto que essa estrutura necessita ser mantida para que toda a base opressora seja conservada.

Não estando imune a todo esse sistema opressor e conservador, a instituição escolar reflete o contexto social em que está inserida, de modo que, em muitos momentos, reforça preceitos que estruturam a base patriarcal, racista e capitalista. Transmitindo uma educação coerente com os interesses da classe dominante, a escola e todo o seu sistema educacional somente será modificado quando tivermos uma sociedade emancipada, fora da lógica do capital e sem interesses de classes (FRERES; RABELO; MENDES SEGUNDO, 2008).

Uma vez que ainda estamos no sistema do capital, as instituições escolares acabam por adotar medidas que naturalizam situações, que aumentam a segregação entre os indivíduos e que corroboram com a opressão. Utilizando-se de preceitos estruturantes da sociedade patriarcal, a escola, por vezes, dissemina conteúdos e metodologias diferenciados para meninas e meninos, além de caracterizar sexualmente os gestos, impondo papéis que reforcem e/ou produzam os sentidos de fragilidade feminina e de raciona- 
QUESTÕES DE GÊNERO NA EDUCAÇÃO FÍSICA ESCOLAR: uma análise nas zonas distritais... Thais Mortola Dias • Giovanni Frizzo

lidade masculina, colaborando, assim, para o binarismo sexista existente (WERNECK, 1996).

Auxiliando em um processo contra essa educação capitalista, a Educação Física (EF) e o seu vasto repertório de conteúdo pode auxiliar no processo de uma formação mais crítica e autônoma, trazendo conteúdos atuais e que proporcionem debates construtivos e sínteses apuradas da realidade. Sendo uma componente curricular que está constantemente voltada para o corpo, a EF também tem um papel fundamental sobre as construções de gênero existentes na escola.

Mesmo com avanços e incessantes lutas emancipatórias, a escola ainda se configura como um lugar de opressão e discriminação (JUNQUEIRA, 2009) e a EF escolar ainda privilegia uma prática baseada na separação (física e simbólica) entre os gêneros (DE LIMA; DINIS, 2008). Nesse sentido, o objetivo deste estudo foi analisar como as questões de gênero são tratadas nas aulas de EF da rede municipal de ensino da cidade de Rio Grande - RS, assim como identificar o posicionamento dos professores e professoras sobre a temática gênero ser trabalhada nas aulas de EF.

\section{Metodologia}

Esta pesquisa tem um viés qualitativo, ancorado em um estudo exploratório e descritivo, a fim de obter dados sobre pessoas, lugares e processos interativos (GODOY, 1995). Realizada na cidade de Rio Grande - RS'1, ela contou com cinco escolas públicas municipais, uma de cada distrito, sendo que, como principal critério de escolha, optou-se pelas maiores em número de alunos e alunas.

Apresentando a pesquisa e as documentações necessárias, todas as escolas aceitaram o convite, disponibilizando o espaço

\footnotetext{
1 Localizado no extremo sul do estado do Rio Grande do Sul, o município é o mais antigo do estado. De médio porte, a cidade de Rio Grande está dividida por cinco distritos, sendo eles: $1^{\circ}$ Distrito - Rio Grande; $2^{\circ}$ Distrito - Ilha dos Marinheiros; $3^{\circ}$ Distrito - Povo Novo; $4^{\circ}$ Distrito - Taim e o $5^{\circ}$ Distrito - Vila da Quinta.
} 
QUESTÕES DE GÊNERO NA EDUCAÇÃO FÍSICA ESCOLAR: uma análise nas zonas distritais... Thais Mortola Dias • Giovanni Frizzo

para investigação. Os/as participantes deste estudo foram de dois grupos distintos: 1) professores e professoras de EF; 2) alunos e alunas do $9^{\circ}$ ano do ensino fundamental; ambos de cada escola investigada. Escolhemos esses sujeitos com a finalidade de alcançarmos variados olhares sobre a temática, além disso, optamos pelos alunos e alunas do $9^{\circ}$ ano do ensino fundamental pelo fato de estes já possuírem um maior tempo de EF escolar, e, consequentemente, maiores subsídios para responder os questionamentos.

Enquanto instrumentos de coleta, escolhemos as entrevistas semiestruturadas e o questionário. As entrevistas, compostas por perguntas abertas e questionamentos básicos, foram realizadas com seis professores e professoras (quatro mulheres e dois homens), sendo que estes/as assinaram o Termo de Consentimento Livre e Esclarecido - TCLE e as concederam de modo individual, dentro de seu âmbito de atuação profissional, a escola. Em outro momento, utilizamos o questionário com os alunos e com as alunas, totalizando 122 questionários respondidos, visto que eles/as assinaram o Termo de Assentimento do Menor - TAM. O questionário continha questões objetivas e foi respondido na própria sala de aula dos/as participantes.

Como metodologia de análise de dados, utilizamos a Análise Textual Discursiva (ATD), visto que esta contém etapas extremamente minuciosas, requerendo do pesquisador a atenção e a rigorosidade em cada momento do processo (DAS NEVES PEDRUZZI et al., 2015).

Ressaltamos também que este estudo respeitou a Resolução 466/12 e os princípios éticos da pesquisa envolvendo seres humanos (BRASIL, 2012), sendo aprovado pelo parecer $n^{\circ}$ 3.098.884. Cabe ainda destacar que todos/as os/as participantes foram convidados a colaborar voluntariamente, assinando o TAM (alunos e alunas) $^{2}$ e o TCLE (professores e professoras), sendo que durante a análise e escrita, com a finalidade de não identificá-los, utilizamos os seguintes pseudônimos: Professora 1, Professora 2, Professora

2 Os/As alunos/as poderiam assinar o termo, mas deveriam levar para os responsáveis darem o consentimento de sua participação. 
QUESTÕES DE GÊNERO NA EDUCAÇÃO FÍSICA ESCOLAR: uma análise nas zonas distritais... Thais Mortola Dias • Giovanni Frizzo

3, Professora 4, Professor 5 e Professor 6, para os/as educadores/ as; Aluno/a B - E333, para alunos e alunas; e ainda E1, E2, E3, E4 e E5, para as escolas.

\section{Os pró e os contra: o que pensam os professores e as professoras sobre as questões de gênero nas aulas de Educação Física}

As questões de gênero estão imersas no nosso contexto social. Sendo uma temática atual em nossa sociedade, torna-se um conteúdo fundamental de ser tratado no âmbito da escola e a EF tem relevante função no desenvolvimento desse conteúdo em suas aulas. Dos Santos (2010) coloca que, ainda que a preocupação com as identidades de gênero esteja presente em todas as situações escolares, na EF talvez ela se torne explícita, visto ser uma área que trabalha diretamente com o corpo, sendo através deste que o gênero se expressa.

Corroborando com isso, uma professora coloca que a "EF ela expõe... Essas questões [...] a EF é ao ar livre, tu tá... Todo mundo tá vendo o que tu tá fazendo, envolve o corpo" (PROFESSORA 3, entrevista, 9 nov. 2019).

Estes/as sujeitos e sujeitas, professores e professoras, têm um papel de protagonista, pois são os que podem ligar a chave da criticidade dos alunos e alunas, ou podem ser os indivíduos que sequer pensam em dar essa partida. A formação acadêmica, ideais e concepções de vida e sociedade são fatores fundamentais no comportamento e postura durante as aulas, seleção de conteúdos e nível de instrumentalização dos docentes perante seus alunos. Instrumentalizar é a ação mais importante dos professores e professoras na escola, pois estes devem orientar o seu aluno e sua aluna para um determinado conteúdo que lhe apresente a ne-

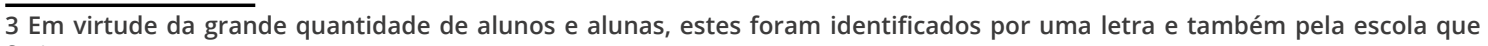
faziam parte. 
QUESTÕES DE GÊNERO NA EDUCAÇÃO FÍSICA ESCOLAR: uma análise nas zonas distritais... Thais Mortola Dias • Giovanni Frizzo

cessidade de solução de um problema nele implícito (CASTELLANI FILHO, L. et al., 2014).

Nesse contexto, perguntamos aos professores e as professoras o que eles e elas pensam sobre as questões de gênero nas aulas de EF, sendo que encontramos dois grupos distintos, os pró-discussão e os contra discussão, dado que apresentamos no quadro a seguir, que evidencia e compara as colocações dos/as participantes:

Quadro 1 - Falas dos professores e das professoras sobre a temática gênero nas aulas de EF

\section{Pró-discussão}

[...] eu acho que dá muito resultado, tanto para a formação do professor [...] Bem positivo (PROFESSORA 1, entrevista, 13 nov. 2019).

Eu acho que interessante né, um espaço para discutir e colocar essas questões [...] Porque eu acho que todo lugar é lugar, né? Mas, eu acho que é importante sim, se tiver algum projeto, seria interessante... (PROFESSORA 2, entrevista, 25 out. 2019).

Eu acho legal, eu acho interessante [...] acho importante. Esses grupos poderiam trabalhar mais, não sei se trabalham em alguma escola, mas aqui eu nunca vi nada nesse sentido... (PROFESSORA 3, entrevista, 9 dez. 2019).

[...] eu acho que as crianças têm que vivenciar a discussão. A escola tem que ser um lugar para discutir e saber o correto... O correto quando eu digo é aquela coisa assim... Que não é o vulgar, que não é o banal, é o lado da ciência mesmo... O quê que é tu gerir uma criança? O quê que é tu cuidar de uma criança? Quê que é tu começar a se interessar pelo... Por outra pessoa... Independente agora do gênero. (PROFESSORA 4, entrevista, 8 out. 2019).

\section{Contra discussão}

Ahh eu acho que é uma coisa muito complicada de se trabalhar na sala de aula, mesmo [...] Eu acho que isso aí, cabe mais assim, a família orientar [...] (PROFESSOR 5, entrevista, 30 out. 2019).

Eu nas minhas aulas, eu procuro nem tocar nesse assunto... Deixo eles brincarem, deixo eles se resolverem... (PROFESSOR 6, entrevista, 2 abr. 2019). 
QUESTÕES DE GÊNERO NA EDUCAÇÃO FÍSICA ESCOLAR: uma análise nas zonas distritais... Thais Mortola Dias • Giovanni Frizzo

Percebemos que no grupo pró-discussão estão as professoras que acreditam ser importante e fundamental a discussão de tal tema nas aulas de EF. Embora em determinados momentos entendam o porquê de haver essa divisão e diferença entre os gêneros, acreditam que os alunos e as alunas devem trabalhar juntos e, se isso não ocorre, se utilizam de estratégias para alcançar a igualdade e amenizar as exclusões. Elas argumentam sobre a sociedade em que vivemos, fazem suas considerações durante as aulas, falando sobre feminismo, machismo e outras problemáticas atuais, ressaltando que o processo foi árduo, mas um avanço já foi conquistado, pois percebem a postura de algumas meninas durante as aulas. Contudo, uma professora destaca que algumas meninas usam da sua dita e imposta fragilidade para não realizarem determinadas atividades, sendo que ela luta intensamente contra isso.

Já no grupo contra a discussão, temos os dois professores que preferem não trabalhar com as questões de gênero, deixando os alunos resolverem (PROFESSOR 6, entrevista, 2 abr. 2019) ou então acreditando que esse assunto está na moda e que não merece discussão dentro do âmbito escolar (PROFESSOR 5, entrevista, 30 out. 2019). Este último professor considera o tema complicado e que caberia à família orientar, pois o assunto poderia ser direcionado de uma maneira equivocada pelos professores. Ainda, relatou que já viveu situação relacionada às questões de gênero na escola, sendo que resolveu através do diálogo com os alunos.

É relevante, nesse ponto, analisarmos o quanto esses professores do grupo contra discussão objetivam um silenciamento da temática gênero dentro do âmbito escolar. Em sua pesquisa, Brancaleoni e Oliveira (2016) concluíram algo análogo quando estavam investigando sobre essa temática dentro da instituição escolar: 
QUESTÕES DE GÊNERO NA EDUCAÇÃO FÍSICA ESCOLAR: uma análise nas zonas distritais...

[...] garantia do enclausuramento dos temas no universo do obsceno, do que não pode ser dito, do que não tem nome, ou como frequentemente ouvia-se "aquelas coisas". Mais uma vez identifica-se o movimento para que as questões relativas à sexualidade e ao gênero ficassem para além dos portões da escola, como se isso fosse possível (BRANCALEONI; OLIVEIRA, 2016, p. 1457).

Em suma, percebemos que os professores e as professoras participantes desta pesquisa têm maneiras distintas de enxergar o mundo e a sociedade em que vivemos. Acreditar que a temática gênero é pertinente de discussão no âmbito escolar mostra o quão alinhado está o pensamento à busca pela transformação do contexto social. Por outro lado, temos os que não apresentam interesse nessa discussão, acreditam que a família tem esse papel, não abrindo espaço para o debate em uma instituição tão importante como a escola, auxiliando, assim, no processo de manutenção da ordem social da lógica do sistema de dominação-exploração.

Todos esses dados nos remetem a voltar ao papel de protagonista que definimos aos professores e às professoras. À estes e estas cabe a centralidade do conhecimento, compete a autonomia para determinar os elementos da cultura corporal a serem trabaIhados, assim como os conteúdos e as temáticas pertinentes de serem expostos para os alunos e as alunas. Castellani Filho et al. $(2014$, p. 15) corrobora nesse aspecto quando apresenta que "todo educador deve ter definido o seu projeto político-pedagógico", ressaltando que estes/as devem saber qual o projeto de sociedade e de indivíduo almeja, quais os interesses de classe que defende e como articula as suas aulas ao projeto de indivíduo e sociedade (CASTELLANI FILHO et al., 2014).

A partir de uma definição, os professores e professoras têm determinada a sua prática na sala de aula:

a relação que estabelece com os seus alunos, o conteúdo que seleciona para ensinar e como o trata científica e metodologicamente, bem como os valores e a lógica que desenvolve nos alunos (CASTELLANI FILHO et al., 2014, p. 15). 
QUESTÕES DE GÊNERO NA EDUCAÇÃO FÍSICA ESCOLAR: uma análise nas zonas distritais... Thais Mortola Dias • Giovanni Frizzo

Nessa perspectiva, percebemos que alguns professores e professoras podem optar por não trabalhar a temática gênero em suas aulas, por terem autonomia de escolha, como acontece com os professores do grupo encontrado na presente pesquisa, o grupo contra discussão. É importante percebermos que a autonomia dos professores e professoras é de grande valia quando direcionada para o crescimento dos alunos e das alunas, almejando êxito na formação humana do indivíduo. No entanto, muitas vezes, esse "poder" somente auxilia no fortalecimento de uma sociedade machista e retrógrada, que não pondera sobre determinadas condutas e que naturaliza ações opressoras, nos fazendo estacionar no sistema atual.

\section{Coisas de menino, coisas de menina: os estereótipos de uma sociedade opressora}

Estereotipar, tipificar, padronizar.... todas essas palavras são sinônimas de categorizar, algo rotineiro nos dias atuais. Constantemente vemos ações que nos reportam a como devemos ser, nos comportar e até mesmo vestir, visto que todas essas ações conduzem a uma vida padronizada harmonicamente com o que foi e é imposto pela sociedade.

Essa imposição é uma reprodução do que se espera dos papéis sociais de homens e mulheres, sobre a qual Kergoat (2002) reflete que tais papéis não são produto de um destino biológico, mas são antes de tudo constructos sociais que têm como bases materiais o trabalho e a reprodução.

Portanto, a sociedade atua como se fosse um diretor de uma peça de teatro, pois indica papéis estereotipados diferentes para homens e mulheres, onde cada um tem que representar fielmente o seu personagem e com clareza, como ordenou o diretor. Saffioti (1987) colabora nesse aspecto quando apresenta que a construção da identidade social da mulher e do homem é feita através da atribuição de distintos papéis que a sociedade espera ver cum- 
QUESTÕES DE GÊNERO NA EDUCAÇÃO FÍSICA ESCOLAR: uma análise nas zonas distritais... Thais Mortola Dias • Giovanni Frizzo

pridos, visto que esta delimita os espaços em que a mulher e o homem podem atuar.

Aproximando-se a essas ponderações, os alunos e as alunas participantes do estudo responderam se existiam atividades de menina e atividades de menino, sendo as respostas expostas no gráfico a seguir (Figura 1):

Figura 1- Opinião dos alunos e das alunas sobre a existência de atividades de meninos e atividades de meninas

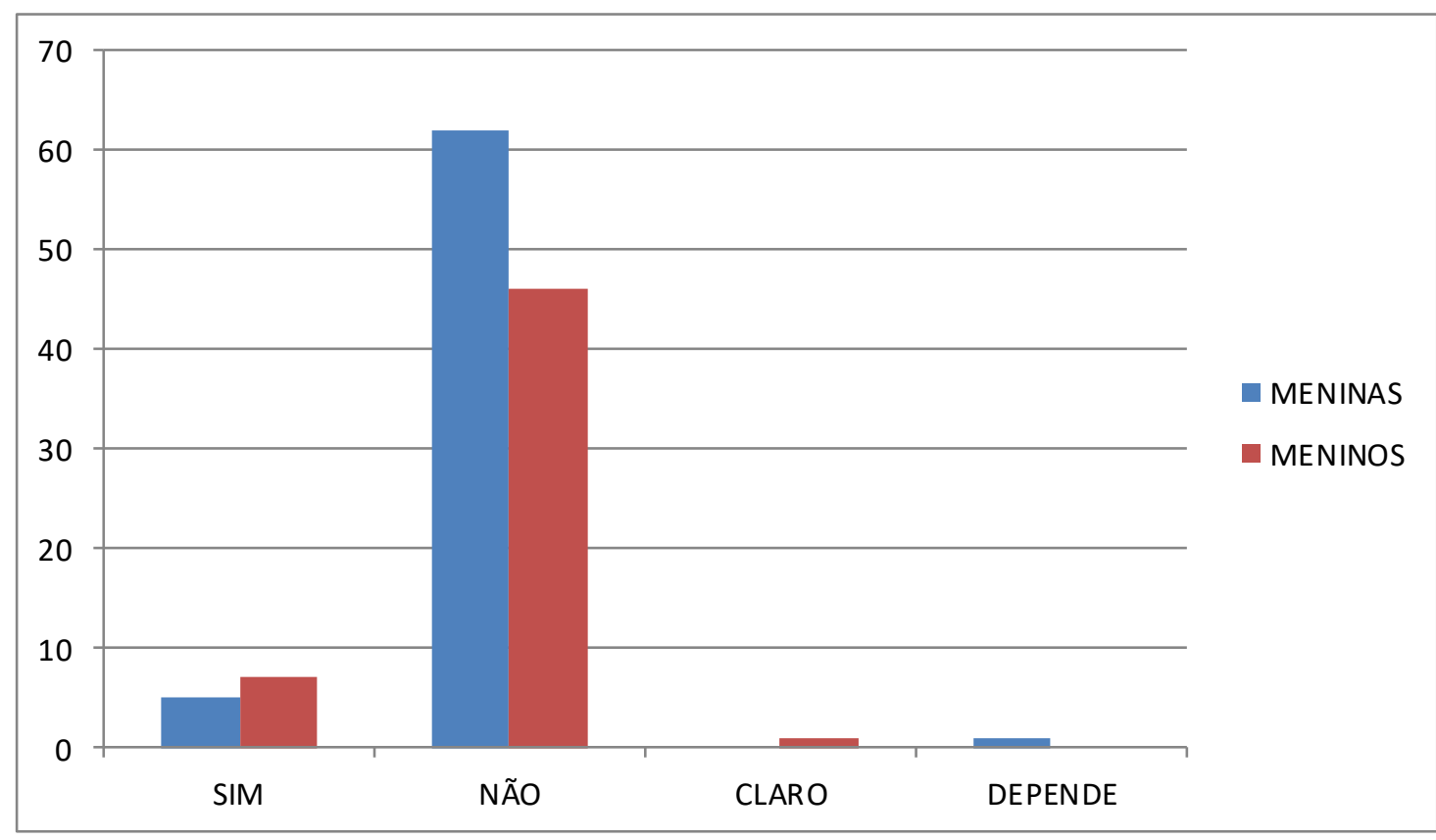

Fonte: Elaborado pelos autores (2021).

Como apresenta a Figura 1, 88\% dos alunos e das alunas acreditam não haver distinção nas atividades, sendo para todos e todas independente do gênero. No entanto, 10\% ainda acreditam que padrões devem ser seguidos e que existem sim atividades de meninos e de meninas. Somaram apenas $2 \%$ os participantes que responderam "depende" e "claro".

Mesmo havendo ampla maioria de alunos e alunas que acreditam não haver distinções nas atividades, ainda encontramos sujeitos que se movimentam de acordo com um padrão imposto e consolidado em nossa sociedade. Em meados de séculos ante- 
QUESTÕES DE GÊNERO NA EDUCAÇÃO FÍSICA ESCOLAR: uma análise nas zonas distritais... Thais Mortola Dias • Giovanni Frizzo

riores, determinou-se que as mulheres fossem o sexo frágil, que serviriam para procriar, cuidar dos filhos e do marido, tornando-se clara, por parte da sociedade, a atribuição do espaço doméstico à mulher (SAFFIOTI, 1987).

Já ao homem foi ordenado que fosse o detentor do poder, os dominadores de mulheres e também de outros homens (SAFFIOTI, 1987). Essa é a base do patriarcado, um forte sistema instalado na sociedade atual, que estando aliado ao capitalismo e ao racismo, luta para que os padrões e rótulos permaneçam, mantendo essa base estrutural opressora.

Tentando perceber o quanto mais essa sociedade estereotipada influencia no âmbito escolar e o quanto a escola internaliza as normas que são colocadas, perguntamos aos professores e professoras se percebiam alguma divisão entre meninos e meninas no momento da prática. Todos/as afirmaram que há uma divisão entre meninos e meninas, sendo que, dentro de algumas diferentes compreensões sobre o porquê isso acontece, percebemos que todas têm a mesma origem.

Seja "por conta da técnica" (PROFESSORA 1, entrevista, 13 nov. 2019); "preferência de jogo" (PROFESSORA 3, entrevista, 9 dez. 2019); "tendência a esportes diferentes entre os gêneros" (PROFESSOR 5, entrevista, 30 out. 2019); ou então "união feminina seja porque não recebem a bola ou para se proteger" (PROFESSOR 6, entrevista, 2 abr. 2019), todos esses fatores nos direcionam ao que afirmou a Professora 2: "reflexo da sociedade, da mulher se submeter, que certos espaços não são dela" (PROFESSORA 2, entrevista, 25 out. 2019).

As mulheres - meninas, nesse caso - dificilmente são ensinadas a jogar futebol ou qualquer outro tipo de esporte, sendo que muitas vezes é através da escola que "conhecem" uma bola. Por conta disso, como ter uma técnica apropriada quando sequer se tem conhecimento do instrumento de jogo, a bola? Como apreciar um esporte que, na maioria das vezes, elas não têm vivência, pois não são incentivadas a praticarem? 
QUESTÕES DE GÊNERO NA EDUCAÇÃO FÍSICA ESCOLAR: uma análise nas zonas distritais... Thais Mortola Dias • Giovanni Frizzo

O tipo de sociedade em que vivemos ensina que as mulheres são o sexo frágil, portanto precisam se unir e se proteger. As meninas, crianças, melhor dizendo, são moldadas a não correr, não jogar, não pular, não vivenciar algumas atividades que são colocadas como "de meninos". Isso reflete nas nossas escolas, e estas, por sua vez, interiorizam esses preceitos, resultando em um espaço permeado de atitudes retrógradas, percepções conservadoras e relações sociais impregnadas de poder patriarcal.

Cisne (2018) coloca que é preciso entender criticamente a cultura e a educação, juntamente com os símbolos e as representações que as permeiam, visto que reproduzem a ideologia patriarcal, corroborando nas desigualdades e diferenciações existentes. Diferenciações essas também investigadas na pesquisa, quando questionado aos alunos e alunas se viam alguma diferença na participação de meninos e meninas nas aulas de EF (Figura 2):

Figura 2: Diferença na participação de meninas e meninos nas aulas de EF

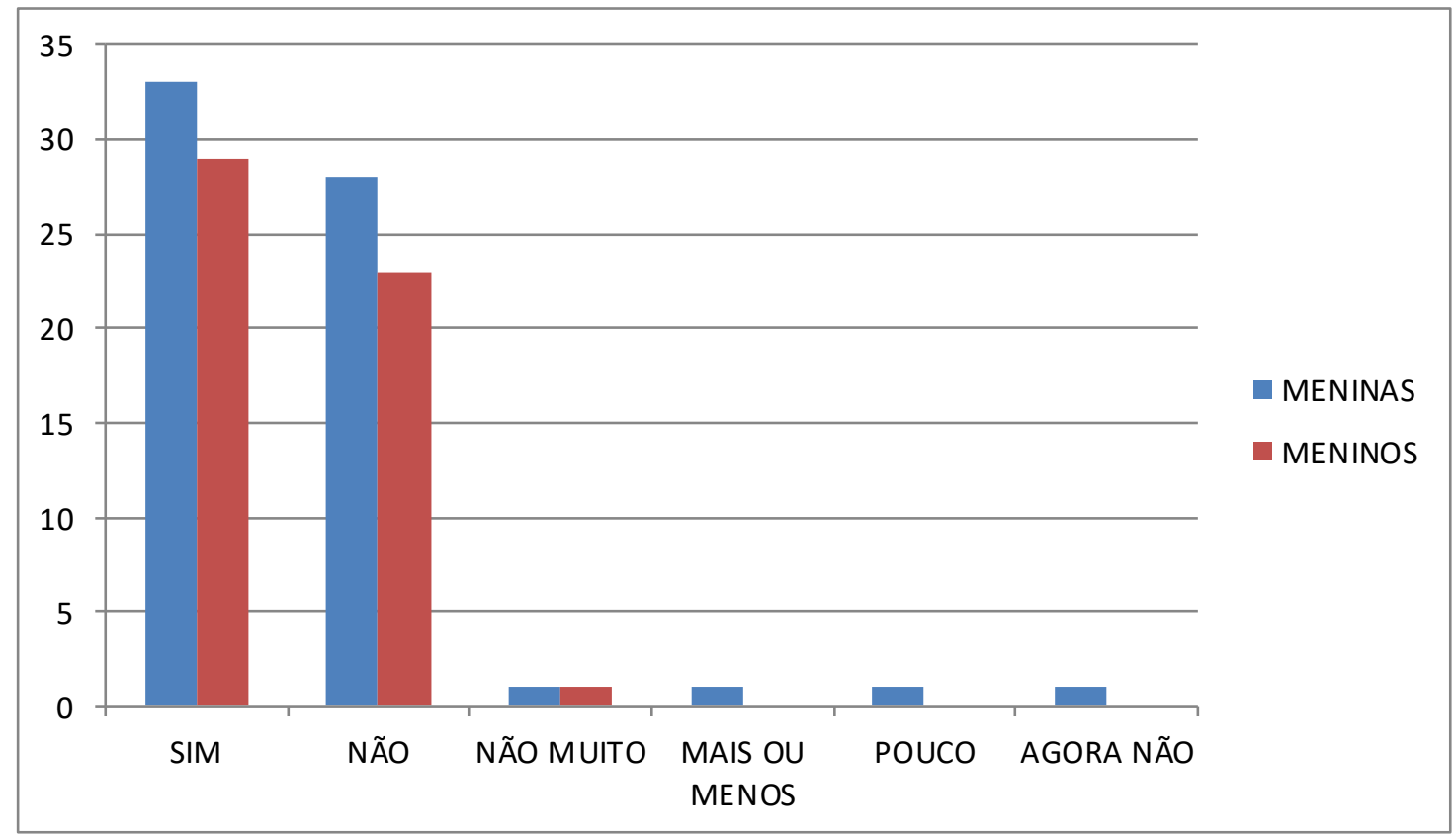

Fonte: Elaborado pelos autores (2021).

Conforme apresentado na Figura 2, 52\% dos participantes da pesquisa consideram haver diferença na participação de meninos 
QUESTÕES DE GÊNERO NA EDUCAÇÃO FÍSICA ESCOLAR: uma análise nas zonas distritais... Thais Mortola Dias • Giovanni Frizzo

e meninas nas aulas de EF. Em contrapartida, 43\% acreditam que não há diferença nas participações, visto que $2 \%$ pensa não haver muito. As meninas ainda colocaram "mais ou menos", "pouco" e "agora não" como respostas, somando assim 3\% no total.

De acordo com as argumentações dos alunos e das alunas, o futebol é uma modalidade esportiva primordial nessa diferenciação. Muitas vezes os meninos já se colocam para realizar tal atividade, enquanto que as meninas não: "dá para ver que as meninas ficam mais no vôlei, basquete, enquanto que os meninos no futebol" (ALUNA I - E1, entrevista, 1 out. 2019). Outra aluna coloca ainda que "muitas meninas se sentem desmotivadas ao jogar futebol e os meninos não sabem jogar em equipe" (ALUNA L - E2, entrevista, 21 out. 2019).

O futebol ainda é considerado um esporte masculino, em que somente os homens podem opinar, argumentar e praticar. Os meninos reproduzem esse padrão, pois colocam barreiras quando as meninas pretendem praticá-lo: "quando é futebol, os meninos não gostam de jogar com as meninas" (ALUNA N - E2, entrevista, 21 out. 2019).

Outras atividades estereotipadas também são determinantes nas diferenciações durante as aulas de EF. Em muitos momentos, os alunos e alunas dizem que existem exercícios próprios para meninas ou que "a maioria dos jogos masculinos são mais agitados que os femininos" (ALUNO A - E2, entrevista, 21 out. 2019).

O estereótipo de mulher frágil e sem habilidade também domina as opiniões dos alunos e das alunas: "porque nós meninos temos que tomar mais cuidado para não machucar as meninas" (ALUNO C - E5, entrevista, 13 nov. 2019); "é que os meninos têm mais vantagens que as meninas" (ALUNO H - E4, entrevista, 6 nov. 2019).

Percebemos que os estereótipos impostos pela sociedade e, muitas vezes, "garantidos" pela instituição escolar são grandes aliados às diferenciações existentes. Como expôs uma aluna, "desde cedo somos ensinados a fazer certas coisas e isso pode aca- 
QUESTÕES DE GÊNERO NA EDUCAÇÃO FÍSICA ESCOLAR: uma análise nas zonas distritais... Thais Mortola Dias • Giovanni Frizzo

bar acontecendo nas aulas de EF" (ALUNA A - E1, entrevista, 1 out. 2019). Essa fala certifica a incorporação, nas aulas de EF, das regras e padrões que o contexto social exige que sigamos.

As mulheres muitas vezes são vistas como incapazes, dependentes, não podendo ocupar todos os espaços, não sendo ainda possível desenvolver sua autonomia, dado que uma aluna coloca: "na maioria das vezes os meninos e o professor escolhem o que a gente vai jogar" (ALUNA K - E1, entrevista, 1 out. 2019). Elas também não conseguem ocupar todos os espaços da escola e, principalmente, das aulas de EF: "mas antes meninas não podiam entrar na quadra, pois tinha meninos jogando" (ALUNA E - E1, entrevista, 1 out. 2019).

Dentro de toda essa conjuntura, identificamos meninas que buscavam modificar esse cenário: "Os meninos não entendem que nós meninas podemos sim ser boa quanto eles" (ALUNA A - E4, entrevista, 6 nov. 2019). Essas meninas pensam de maneira inversa ao que é colocado como padronizado, sendo elas peças fundamentais no processo de extinção dessa sociedade patriarcal.

\section{“Não tão declarada, mas ela existe": as opressões nas aulas de Educação Física}

Oprimir outrem. Esta é uma ação recorrente na sociedade atual, sendo praticada por diversos sujeitos que acreditam em suas múltiplas opressões e as sustentam com argumentos frágeis e levianos. Essas múltiplas opressões são cultivadas pelo modelo de sociedade patriarcal-racista-capitalista (CISNE, 2018) que vivemos, onde o opressor acredita ser o "dono da verdade", podendo oprimir deliberadamente.

Nesse modelo de sociedade que Cisne (2018) nos apresenta, é importante pensar que algumas opressões se interseccionam, influenciando umas às outras. Essa mesma autora aponta que as diversas opressões são determinadas estruturalmente pelas rela- 
QUESTÕES DE GÊNERO NA EDUCAÇÃO FÍSICA ESCOLAR: uma análise nas zonas distritais... Thais Mortola Dias • Giovanni Frizzo

ções sociais de sexo (e sexualidade), raça e classe, que de maneira dialética e imbricada configuram as múltiplas expressões da questão social, tanto na sua dimensão de desigualdade, como na de resistência política (CISNE, 2018, p. 212).

Visto isso, partimos do pressuposto que a escola é uma instituição que reflete a sociedade, assim como constitui relações pedagógicas que internalizam normas e regras dessa sociedade. Corroborando com isso, Bento (2011) afirma que:

\begin{abstract}
A escola, que se apresenta como uma instituição incapaz de lidar com a diferença e a pluralidade, funciona como uma das principais guardiãs das normas de gênero e produtoras da heterossexualidade. Para os casos em que as crianças são levadas a deixar a escola por não suportarem o ambiente hostil, é limitador falarmos em evasão (BENTO, 2011, p. 555).
\end{abstract}

Nesse sentido, averiguamos se as opressões existentes também fazem parte do contexto das aulas de EF das escolas investigadas.

Focando nas opressões de gênero, uma professora esclarece que estas ocorrem de forma "Não tão declarada, ela existe, mas é velada..." (PROFESSORA 1, entrevista, 13 nov. 2019). Ainda nas escolas investigadas, uma professora apresenta que "se deixar livre é claro que alguns seguem com isso mais forte dentro deles né... Que isso aí vem da família" (PROFESSORA 2, entrevista, 25 out. 2019), ou seja, reflete o contexto social que vivem. Reforçando isso, a Professora 3 colocou que "talvez sim [...] os pequenos estão naquela fase assim de ah, guri odeia guria [...] as gurias são ruins, as gurias são fracas" (PROFESSORA 3, entrevista, 9 dez. 2019).

O forte sistema patriarcal instaurado se reflete nas aulas, sendo que este apresenta o homem como um ser mais "forte" (que pode praticar esportes de forte contato e rispidez, como o futebol), logo, digno de posições de prestígio e maior importância (escolhem os times e determinam quem joga) e a mulher como mais "fraca" (que pode praticar esportes sem contato e que sejam 
QUESTÕES DE GÊNERO NA EDUCAÇÃO FÍSICA ESCOLAR: uma análise nas zonas distritais... Thais Mortola Dias • Giovanni Frizzo

mais delicados e menos ríspidos, como voleibol ou brincadeiras), logo, impossibilitada para determinadas coisas e ocupando papéis secundários da vida em sociedade (não tomam decisões, sendo submissas) (OLIVEIRA, n. d.). Embasadas nisso, as aulas são dadas, onde, na maioria dos casos, os sujeitos envolvidos sequer contestam essa situação devido a sua naturalização perante esses fatos.

No entanto, temos os professores que consideram não haver opressões em suas aulas de EF, afirmando que ali e em outras escolas em que trabalharam, nunca viram nada disso (PROFESSOR 5, entrevista, 30 out. 2019), ou que não sentem essa separação (PROFESSOR 6, entrevista, 2 abr. 2019).

Colaborando com isso, embora a Professora 1 acredite que as opressões de gênero são presentes em suas aulas, considera que

o que importa é a técnica, porque no fundo [...] eles se preocupam é com a técnica, se a maioria das gurias tivesse uma técnica boa, né ou satisfatória [...] eu acho que eles nem iam pensar em menino e menina" (PROFESSORA 1, entrevista, 13 nov. 2019).

Continuando, ela diz que:

Enquanto a menina com 5 anos está ali brincando de boneca, porque é o que dão... o menino já tá chutando bola, ele já tá lá... tendo outras vivências... pensem... olha o que de defasagem vocês tem em relação aos meninos (PROFESSORA 1, entrevista, 13 nov. 2019).

Abreu (1992) identificou as opressões de gênero tem raízes culturais, pois irmãos e irmãs tendem a receber uma educação diferenciada, com os meninos dispondo de mais tempo livre para brincadeiras, enquanto as meninas são mais solicitadas pelas mães para ajudarem nos afazeres domésticos, tendo menos tempo livre para brincar, vivenciando experiências motoras mais tarde, nas aulas de EF. 
QUESTÕES DE GÊNERO NA EDUCAÇÃO FÍSICA ESCOLAR: uma análise nas zonas distritais... Thais Mortola Dias • Giovanni Frizzo

A fim de compreender mais amplamente as opressões nas aulas de $E F$, perguntamos aos alunos e às alunas se ocorre algum tipo de preconceito/constrangimento nas aulas de EF (Figura 3):

Figura 3: Percepção dos alunos e das alunas sobre preconceito/ constrangimento nas aulas de EF

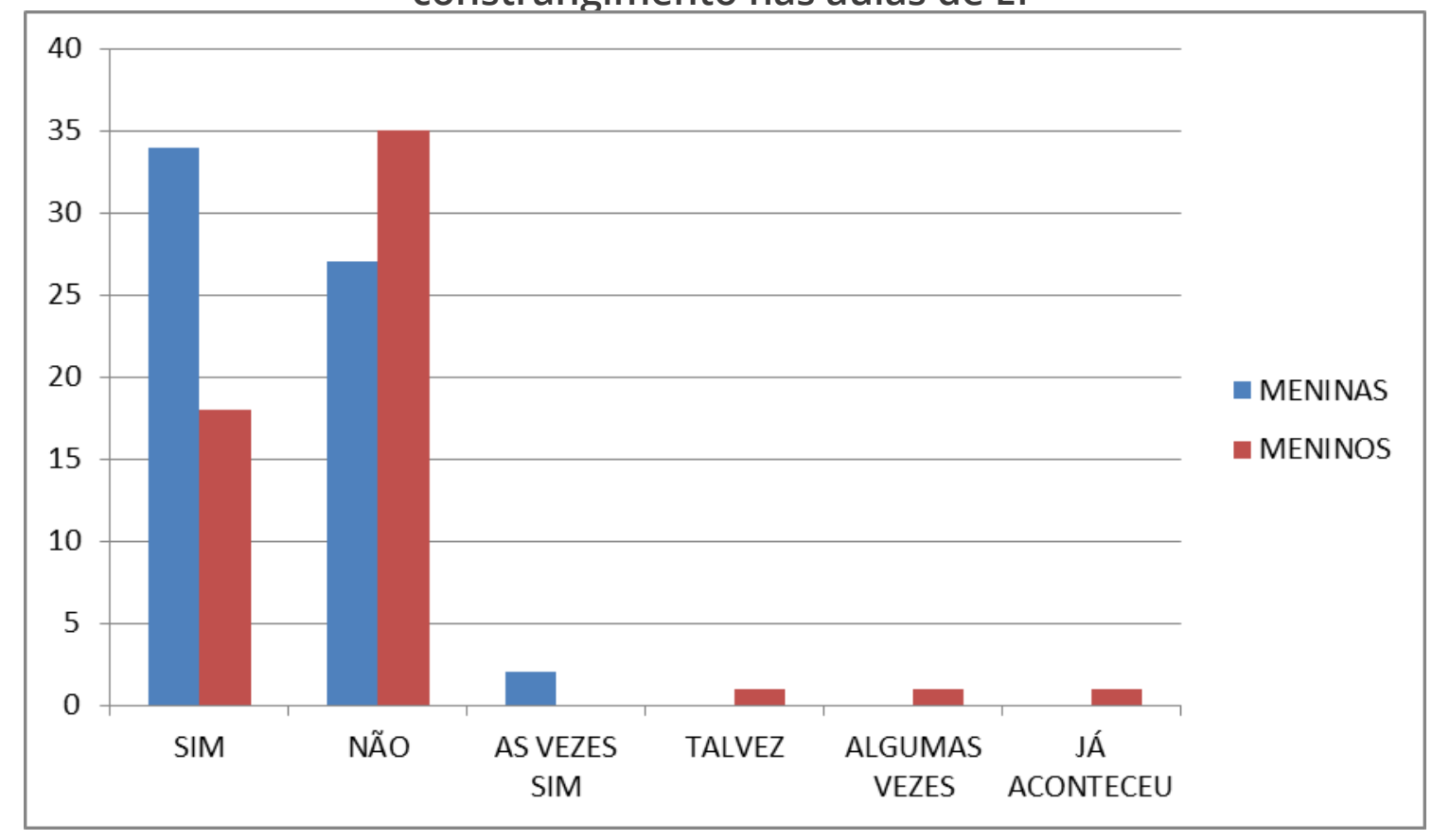

Fonte: Elaborado pelos autores (2021).

Entre os alunos e as alunas participantes da pesquisa, 43\% afirmaram que há sim preconceito/constrangimento nas aulas de EF. As respostas "às vezes sim", "talvez", "algumas vezes" e "já aconteceu" somam um total de $5 \%$, percebendo que, de certa forma, ocorre esse tipo de situação nas aulas em questão. Com outra perspectiva, 52\% dos/as participantes acreditam que não há esse preconceito/constrangimento nas aulas de EF.

Através de seus argumentos, os alunos e as alunas apresentaram os porquês de haver esse preconceito/constrangimento nas aulas, sendo que, para melhor apresentá-los, ressaltamos as circunstâncias e/ou práticas que mais causam esse tipo de situação.

Como mais falado, o futebol é uma prática que levanta inúmeras discussões e causa variadas situações complexas no mundo 
QUESTÕES DE GÊNERO NA EDUCAÇÃO FÍSICA ESCOLAR: uma análise nas zonas distritais... Thais Mortola Dias • Giovanni Frizzo

escolar. Quando perguntados, muitos argumentos foram apresentados, argumentos esses que mostravam o quanto o futebol é uma ferramenta que pode causar a opressão e exclusão durante as aulas de EF: "Os meninos não deixam as meninas jogar futebol" (ALUNA A - E1, entrevista, 1 out. 2019); "Os guris jogando futebol e as gurias não poderem jogar" (ALUNA C - E1, entrevista, 1 out. 2019).

Os estereótipos também predominam nas situações apresentadas. "Mulher frágil", "atividades de menino", "atividades de menina", "menina não sabe jogar" permeiam o espaço escolar e principalmente as aulas de EF: "ocorre em relação à mulher ser inferior" (ALUNO X - E1, entrevista, 1 out. 2019); "pelo fato dos meninos algumas vezes não deixarem as meninas jogar por sermos do sexo oposto ao deles" (ALUNA L - E3, entrevista, 25 out. 2019).

O padrão ideal de corpo é uma imposição da sociedade, sendo algo que se reflete e que, muitas vezes, é reforçado no âmbito escolar, ocorrendo assim durante as aulas de EF, causando situações de constrangimento e exclusão: "quando mais novo eu era gordo e alguns achavam que eu era incapaz de realizar atividades normalmente" (ALUNO R - E1, entrevista, 1 out. 2019).

Constrangimento sofrem também algumas meninas diante de determinadas atividades, relatando que: "em algumas aulas temos que fazer agachamento e flexões, coisas que deixam algumas de nós bem desconfortáveis" (ALUNA B - E1, entrevista, 1 out. 2019).

A escola, para além de refletir as opressões da sociedade atual, corrobora para que isso aconteça, pois não recrimina tais atitudes e situações. As meninas, como podemos constatar através das falas dos alunos e das alunas, são as mais oprimidas. Saffioti (1984, p. 20) ressalta que "as mulheres são duplamente marginalizadas: por sua classe social e por seu sexo". Nesse contexto, assegura-se dizer que a mulher pode chegar a ser triplamente marginalizada quando inserimos a categoria raça.

A autora supracitada ainda coloca que os preconceitos são, assim, utilizados racionalmente a fim de dar lugar à dimensão opres- 
QUESTÕES DE GÊNERO NA EDUCAÇÃO FÍSICA ESCOLAR: uma análise nas zonas distritais... Thais Mortola Dias • Giovanni Frizzo

siva da posição de inferioridade da mulher, visto que a condição de oprimida manifesta-se, sobretudo, na divisão social do trabaIho, processo através do qual se viabiliza sua exploração (SAFFIOTI, 1984).

Frente a toda essa conjuntura, os professores e as professoras foram questionados sobre como trabalham se ocorre alguma situação relacionada a gênero e opressão durante as suas aulas. A maioria relatou que consegue resolver através do diálogo: "Sempre tento conversar, com o agressor [...] trazendo um pouco da consciência dele" (PROFESSORA 1, entrevista, 13 nov. 2019). A Professora 3 coloca ainda que "vejo o lado, a versão de cada um e tento né, contornar a situação da melhor maneira" (PROFESSORA 3, entrevista, 9 dez. 2019).

Percebemos que as opressões são identificadas e que algumas professoras se importam com a luta de emancipação das muIheres. No entanto, ainda temos sujeitos que sequer percebem tal ato como opressão. Ferreira (2015, p. 367), em se tratando das opressões de gênero contra as mulheres, expõe que está em um nível "[...] que as próprias mulheres reproduzem ou se tornam cúmplices de seus agressores".

Nesse sentido que é fundamental problematizar essa cultura conservadora e retrógrada, que é baseada no patriarcado e no capitalismo, sendo também permeada de ações racistas. É preciso compreender as relações dentro desse sistema de exploração-dominação, percebendo as múltiplas formas de opressão (SAFFIOTI, 2004). É preciso dar voz às minorias, criticar o sistema político-econômico, contestar os argumentos obsoletos e não deixar naturalizarem as opressões. É preciso movimentar a sociedade, levando-a ao caminho da luta pelos seus direitos e pelo respeito. É preciso uma contraposição da instituição escolar frente a toda essa lógica opressora. Este é um rumo certo para alcançar com êxito uma sociedade mais igualitária, justa e livre. 
QUESTÕES DE GÊNERO NA EDUCAÇÃO FÍSICA ESCOLAR: uma análise nas zonas distritais... Thais Mortola Dias • Giovanni Frizzo

\section{Conclusão}

No que tange sobre as questões de gênero serem trabalhadas nas aulas de EF, constatamos que os professores e as professoras têm diferentes percepções, formando dois grupos distintos: os pró-discussão (os que entendem a importância que há em trabaIhar a temática); e os contra discussão (os que acreditam que essa temática não deve ser tratada na escola).

Sobre os estereótipos do contexto social vigente, os alunos e as alunas, em sua maioria, acreditam não haver distinção nas atividades, no entanto, alguns ainda pensam que padrões devem ser seguidos e que existem sim atividades de meninos e de meninas. Além disso, constatamos através das falas que há uma divisão e uma diferenciação entre meninos e meninas no momento da prática, tendo como fatores determinantes para isso: o futebol e os estereótipos impostos pela sociedade.

Percebemos ponderações distintas sobre as opressões nas aulas de EF. A maioria das professoras apresenta que as opressões existem sim, mas que não são expostas de forma tão declarada; em contraponto, os professores consideram que não há e que nunca constataram isso durante sua trajetória de ensino. Já entre os alunos e as alunas, a maioria acredita que não há, contudo, alguns consideram que, em determinados momentos, isso ocorre e que as principais causas, segundo o relato das meninas participantes, são: o futebol; os estereótipos e algumas atividades constrangedoras.

Identificamos também que a escola reflete o contexto social, sendo ainda um espaço que segrega, diferencia e oprime os sujeitos. No entanto, por mais que seja difícil uma emancipação na lógica do sistema do capital, entendemos que as instituições escolares poderiam assumir um papel que vai contra esse sistema opressor, interiorizando preceitos que auxiliassem na emancipação de todos e todas ali presentes. 
QUESTÕES DE GÊNERO NA EDUCAÇÃO FÍSICA ESCOLAR: uma análise nas zonas distritais... Thais Mortola Dias • Giovanni Frizzo

Por fim, gostaríamos de salientar que este artigo apresenta as suas limitações, uma vez que analisou as questões de gênero a partir das perspectivas dos/as participantes, não havendo observações dos espaços investigados. Além disso, as conclusões aqui apresentadas dizem respeito às escolas pesquisadas, ao universo destas, não podendo, assim, ser ampliadas a outros universos escolares.

\section{Referências}

ABREU, N.G. Meninos pra cá, meninas pra lá? In: VOTRE, S. J.

(org.). Ensino e avaliação em Educação Física. São Paulo: Ibrasa, 1992. p.101-120.

BENTO, B. Na escola se aprende que a diferença faz a diferença.

Revista Estudos Feministas, Florianópolis, v. 19, n. 2, p. 549-559, ago. 2011. Disponível em: http://www.scielo.br/pdf/ref/v19n2/ v19n2a16.pdf. Acesso em: 7 maio 2021.

BRANCALEONI, A. P. L.; OLIVEIRA, R. R. de. Silêncio! Não desperte os inocentes: sexualidade, gênero e educação sexual a partir da concepção de educadores. Revista Ibero-Americana de Estudos em Educação, Araraquara, v. 10, n. esp. 2, p. 1445-1462, 2016. Disponível em: https://periodicos.fclar.unesp.br/iberoamericana/ article/view/8330. Acesso em: 7 Maio 2021.

BRASIL. Ministério da saúde; conselho nacional de saúde. Resolução n. 466, de 12 de dezembro de 2012. Aprova diretrizes e normas regulamentadoras de pesquisas envolvendo seres humanos. Brasília, Diário Oficial da União, 12 dez. 2012.

CASTELLANI FILHO, L. et al. Metodologia do ensino de Educação Física. Cortez Editora, 2014.

CISNE, M. Feminismo e marxismo: apontamentos teórico-políticos para o enfrentamento das desigualdades sociais. Serviço Social \& Sociedade, São Paulo, s. v., n. 132, p. 211-230, 2018. 
QUESTÕES DE GÊNERO NA EDUCAÇÃO FÍSICA ESCOLAR: uma análise nas zonas distritais... Thais Mortola Dias • Giovanni Frizzo

DAS NEVES PEDRUZZI, A. et al. Análise textual discursiva: os movimentos da metodologia de pesquisa. Atos de pesquisa em Educação, Blumenau, v. 10, n. 2, p. 584-604, 2015.

DE LIMA, F. M.; DINIS, N. F. O discurso sobre a homossexualidade na visão de estudantes de Educação Física. Perspectiva, Florianópolis, v. 26, n. 2, p. 693-716, 2008.

DOS SANTOS, V. C. Indícios de sentidos e significados de feminilidade e de masculinidade em aulas de Educação Física. Motriz. Journal of Physical Education. UNESP, Rio Claro, v. 16, n. 4, p. 841-852, 2010.

FERREIRA, A. C. S. Gênero e relações de opressão: breves reflexões. Periódico do Núcleo de Estudos e Pesquisas sobre Gênero e Direito Centro de Ciências Jurídicas - Universidade Federal da Paraíba., João Pessoa, v. 4, n. 1, p. 358-370, - Ano 2015. FRERES, H.; RABELO, J.; MENDES SEGUNDO, M. O papel da educação na sociedade capitalista: uma análise onto-histórica. In: CONGRESSO BRASILEIRO DE HISTÓRIA DA EDUCAÇÃA, s. n., 2008, Acarajé. Anais [...]. Acarajé: Universidade de Tiradentes, 2008. p. 1-15.

GODOY, A. S. Introdução à pesquisa qualitativa e suas possibilidades. RAE-revista de administração de empresas, São Paulo, v. 35, n. 2, p. 57-63, 1995.

JUNQUEIRA, R. Homofobia na escola: um problema de todos. In: OUANE, A., et al. Diversidade Sexual na Educação: problematizações sobre a homofobia nas escolas. Brasília: MEC/ Unesco, v. 32, p. $13-53,2009$.

KERGOAT, D. A relação social de sexo da reprodução das relações sociais à sua subversão. Pro-posições, Campinas, v. 13, n. 1, p. 47-59, 2002.

MARTINS, A. P. V. Possibilidades de diálogo: classe e gênero. História Social, Campinas, v. 4, n. 5, p. 135-156, 1998.

OLIVEIRA, M. A. Educação Física e equidade de gênero: perspectivas e possibilidades. [S.I] [n.d] Disponível em: http://www.diaa- 
QUESTÕES DE GÊNERO NA EDUCAÇÃO FÍSICA ESCOLAR: uma análise nas zonas distritais... Thais Mortola Dias • Giovanni Frizzo

diaeducacao.pr.gov.br/portals/pde/arquivos/771-4.pdf. Acesso em: 25 fev. 2020.

SAFFIOTI, H. I. B. Mulher brasileira: opressão e exploração. Rio de Janeiro: Achiamé, 1984.

SAFFIOTI, H. I. B. O poder do macho. São Paulo: Editora Moderna, 1987.

SAFFIOTI, H. I. B. Gênero, patriarcado, violência. São Paulo: Editora Fundação Perseu Abramo, 2004.

WERNECK, C. L. G. Dissimulação do uso social e político do corpo na Educação Física. In: Coletânea. $3^{\circ}$ Congresso LatinoAmericano de Esporte, Educação e Saúde no movimento humano. Cascavel: Gráfica Universitária. 1996. p. 139-149.

\section{Publisher}

Universidade Federal de Goiás. Faculdade de Educação Física e Dança. Publicação no Portal de Periódicos UFG. As ideias expressadas neste artigo são de responsabilidade de seus autores, não representando, necessariamente, a opinião dos editores ou da universidade. 